\title{
Diploidy of Drosophila imaginal cells is maintained by a transcriptional repressor encoded by escargot
}

\author{
Naoyuki Fuse, ${ }^{1}$ Susumu Hirose, ${ }^{2}$ and Shigeo Hayashi ${ }^{3-5}$ \\ ${ }^{1}$ The Graduate University for Advanced Studies, ${ }^{2}$ Department of Developmental Genetics, ${ }^{3}$ DNA Research Center, National \\ Institute of Genetics, Mishima, Shizuoka-Ken 411, Japan
}

\begin{abstract}
The Drosophila escargot (esg) gene encodes a $\mathrm{C}_{2}-\mathrm{H}_{2}$-type zinc finger protein that is expressed in the imaginal discs and histoblasts. In some esg mutants, the abdominal histoblasts become polyploid. It has therefore been suggested that the role of $e s g$ is to maintain diploidy of the imaginal cells. We show that esg encodes a DNA-binding protein with high affinity for G/ACAGGTG, the consensus-binding sequence for the basic helix-loop-helix (bHLH) family of transcription factors (E2 box). This DNA-binding activity is essential for esg function in vivo as the strong embryonic lethal allele $e g^{\mathrm{vS} 8}$ is caused by an amino acid change within the zinc finger region, leading to reduced affinity for DNA. In cultured cells, a heterodimer of the bHLH proteins Scute and Daughterless activates transcription from promoters containing E2 boxes. The esg protein strongly inhibits this activation, suggesting that esg may regulate developmental processes dependent on bHLH proteins. In larvae, esg protein expressed by the heat shock promoter can rescue the polyploid phenotype of abdominal histoblasts, demonstrating that the phenotype is attributble to a loss of esg function. esg must be expressed continuously during the larval period for efficient rescue. Ectopic expression of esg in the salivary glands inhibits endoreplication of DNA. These results suggest that esg is involved in transcriptional inhibition of genes required for endoreplication.
\end{abstract}

[Key Words: escargot; imaginal development; diploidy; transcription factor; E2 box]

Received June 10, 1994; revised version accepted August 10, 1994.

The maintenance of ploidy is essential for the inheritance of a constant amount of genetic material during cell proliferation. This is accomplished by the alternation of DNA replication (the $S$ phase) and the equal partitioning of the replicated DNA to the daughter cells / the $\mathrm{M}$ phase). Progression through this mitotic cycle is coordinated by a group of cyclin-dependent protein kinases (cdc2 and cdks; for review, see Sherr 1993) and protein phosphatases. These and other evolutionarily conserved regulators are thought to ensure that the $S$ phase always comes after completion of the $M$ phase and that the $M$ phase always comes after completion of the $S$ phase. Such regulations are called checkpoint controls (Hartwell and Weinert 1989). However, some cells in a multicellular organism may escape from this regulation during terminal differentiation and may repeat the $S$ phase without mitosis to become large polyploid cells. Megakaryocytes of the hematopoietic cell lineage and the giant cells of the placenta in which chromosome becomes polytene (Varmuza et al. 1988) are examples in mammals. This cell cycle without mitosis is called the endo

\footnotetext{
${ }^{4}$ Present address: Genetic Stock Center, National Institute of Genetics, Mishima, Shizuoka-ken 411, Japan.

${ }^{5}$ Corresponding author.
}

cycle, the $\mathrm{S}$ phase of which is called endoreplication. Normal checkpoint controls must be modified in the endo cycle.

The insect larva provides a unique opportunity to study how cells choose whether to grow by the mitotic or by the endo cycle during development. In Drosophila, most of the larval cells do not undergo mitosis after completion of embryogenesis but, instead, undergo repeated endo cycles to become large polyploid cells. These polyploid larval cells have a limited ability to differentiate and are mostly histolyzed during metamorphosis. However, the imaginal cells (the imaginal discs and the histoblasts) that give rise to the adult first appear during mid-embryogenesis (Bate and Martinez-Arias 1991; Cohen et al. 1991; Hartenstein and Jan 1992; YounossiHartenstein et al. 1993), remain diploid, and proliferate during larval or pupal stages. At metamorphosis, they replace the larval cells to form the adult (for review, see Cohen 1993). Thus, maintenance of diploidy is an essential requirement for proliferation and differentiation of imaginal cells.

The head, thorax, and genitalia of the adult are derived from the imaginal discs - sac-like epithelial invaginations of the larval epidermis. The imaginal disc cells proliferate during the larval period. At metamorphosis the 
discs evert and secrete the adult cuticle. The imaginal disc of Drosophila is a highly specialized structure. It grows and differentiates largely independent of the larval cells as revealed by in vivo culture experiments (Bryant 1978). A more primitive form of the imaginal cell is found in the precursors of the adult abdomen-the abdominal histoblast nests. The abdominal histoblasts originate from the same ectodermal cells as the larval epidermis (Hartenstein and Jan 1992; Whiteley et al. 1992, Hayashi et al. 1993) and form nests of diploid cells within the larval epidermis (Roseland and Schneiderman 1979). The abdominal histoblasts have many of the characteristics of the larval epidermal cells but retain the ability to differentiate further. These histoblasts participate in larval growth by secreting cuticle, and upon metamorphosis, proliferate to replace the larval epidermis and secrete the adult cuticle (Roseland and Schneiderman 1979|. Because of their common origin and properties, the abdominal histoblasts may be considered a specialized form of the larval epidermal cell, maintaining developmental potential, or "imaginal state" by a mechanism currently unknown.

The escargot (esg) gene encodes a putative zinc finger transcription factor (Whiteley et al. 1992) and is expressed in most of the adult primordia found in the late embryo (Hartenstein and Jan 1992; Whiteley et al. 1992; Hayashi et al. 1993; Younossi-Hartenstein et al. 1993). We have shown previously that in some heteroallelic esg mutant combinations, the abdominal histoblasts in the larva become polyploid and fail to form the adult abdomen (Hayashi et al. 1993). In addition, some imaginal disc cells become polyploid when $e$ s function is reduced and the mitotic cycle is arrested simultaneously by a mutation in the raf gene. From these results we suggested that esg may play an essential role in the maintenance of the imaginal state by inhibiting endoreplication in the imaginal cells.

However, important questions remain unanswered. Does esg control entry into and/or progression through the endo cycle directly or is esg involved in a more general system maintaining the imaginal state? We also wish to understand the molecular mechanism of regulation by esg. To address these issues, we must understand the molecular nature of the esg product and what cellular processes it regulates directly. In this report we show that esg protein is a transcriptional regulator that preferentially binds to G/ACAGGTG in vitro and antagonizes transcriptional activation by basic helix-loop-helix (bHLH) proteins in cultured cells. When expressed in larva, esg inhibits endoreplication. We propose that esg regulates the transcription of genes that control entry into endoreplication.

\section{Results}

esg protein binds to the E2 box

The presence of zinc finger motifs in the putative esg protein suggests that the primary function of esg protein is to bind to a specific DNA sequence and regulate tran- scription. To test this idea, the DNA-binding ability of esg protein and its optimal binding sequence were determined. The carboxy-terminal 165-amino-acid fragment of esg protein (Esg) that includes five zinc finger repeats was produced in bacteria. In a preliminary gel mobility retardation experiment this protein showed DNA-binding activity. Optimal binding sequences were selected from a pool of random sequence oligonucleotides (see Materials and methods). The consensus sequence derived from the selected oligonucleotides was G/ACAGGTG, which is identical to the E2 box; the consensus sequence for a family of bHLH proteins (Fig. 1A). The specificity of Esg binding to this sequence was examined by a competition assay. Esg was found to bind to the E2 box with high affinity (dissociation constant, $2.7 \times 10^{-10}$ $M$; see Materials and methods). Base changes within the E2 box abolished the binding (Fig. 1C). The specificity was also confirmed by a DNase I protection assay (Fig. $1 \mathrm{~B}, \mathrm{D})$. Because bHLH proteins are known to bind to the E2 box as either homo- or heterodimers (Murre and Baltimore 1992), we determined whether Esg will also bind to the $\mathrm{E} 2$ box as a dimer. The carboxy-terminal portion of the esg protein was fused to glutathionine $S$-transferase (GST-Esg) and used in a gel mobility retardation experiment. Esg and GST-Esg formed complexes with different mobilities. If these proteins bind DNA as an oligomer, a mixture of these proteins is expected to form a complex with an intermediate mobility (Hope and Struhl 1987). We were unable to detect such a complex after 16 hr of preincubation, indicating that the recombinant esg proteins did not form oligomers when bound to DNA. From these results, we conclude that esg protein binds to the $\mathrm{E} 2$ box as a monomer with high affinity.

\section{esg antagonizes transcriptional activation by $b H L H$ proteins}

We then tested whether esg regulates transcription of promoters containing the E2 box. In Drosophila, proneural bHLH proteins encoded by the genes in the achaetescute complex form heterodimers with the ubiquitous daughterless protein (Da; Murre et al. 1989). The heterodimers then bind to the E2 box and activate transcription of their target genes (Cabrera and Alonso 1991; Doren et al. 1992; Murre and Baltimore 1992). esg protein that can bind to the same E2 box may affect such transcriptional activation. To analyze such interactions in a simplified tissue culture system, we made a reporter gene with three E2 boxes placed upstream of a minimal promoter and the bacterial chloramphenicol acetyltransferase (CAT) gene and assayed its expression in Schneider line 2 (S2) cells. We chose scute protein (Sc) and Da as a bHLH heterodimer acting on this reporter gene. It has been shown that cotransfection of $s c$ and $d a$ expression vectors stimulates transcription from the ac promoter that contains the E2 box (Doren et al. 1992). The presence of the E2 box did not affect the basal promoter activity, and no esg protein was detectable in $\mathrm{S} 2$ cells by immunostaining before transfection (data not shown). As shown in Figure 2B, cotransfection with the esg ex- 

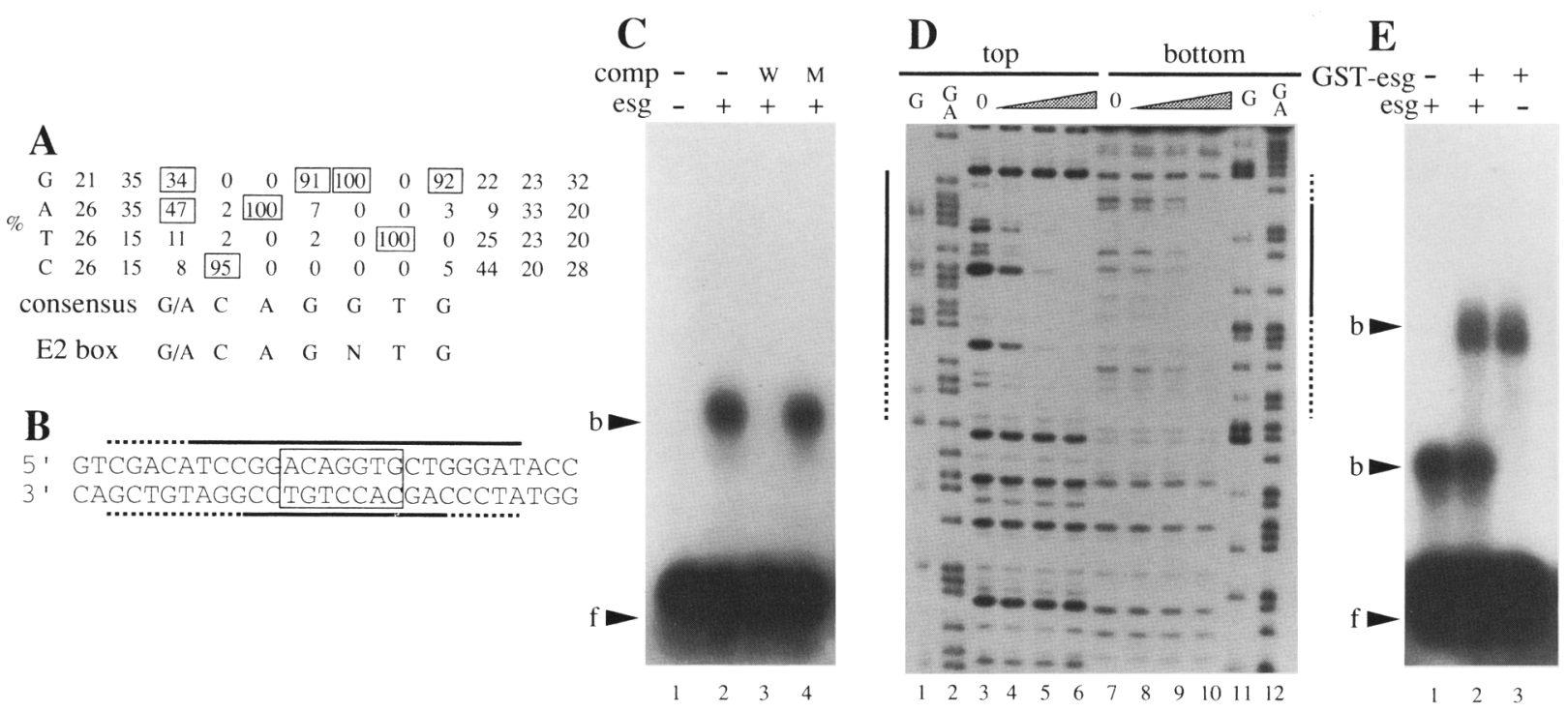

Figure 1. DNA-binding properties of esg. $(A)$ The esg consensus-binding sequence. The sequence of 49 clones selected from a pool of random oligonucleotides by the gel mobility retardation assay were aligned to derive the consensus sequence shown below. The frequency of each base at each position is shown by percentage, and the bases found most frequently are boxed. The E2 consensus sequence is shown below. $(B)$ The sequence of one of the selected clones used for the DNase I protection assay shown in $D$. The esg consensus sequence is boxed. Strong and weak protection sites are marked by continuous and broken lines, respectively. $(C)$ Sequence specificity. An oligonucleotide containing the esg consensus sequence (the wild type probe) was used in a gel mobility retardation assay. Free probe (f) and DNA-protein complex (b) are indicated by arrowheads. Ten fmoles of an oligonucleotide probe and 300 pg of Esg in $10 \mu \mathrm{l}$ of binding buffer were loaded in each lane. (Lane 1) No protein control; (lane 2) a binding reaction without competitor. Samples for lanes 3 and 4, contained 100-fold molar excess of unlabeled competitor DNA with the wild-type (lane 3) and the mutant sequence (lane 4). The mutant has 5 base changes within the E2 box. $(D)$ DNase I protection assay. The probe shown in $B$ was end-labeled and 5 fmoles was used for each assay. The top (lanes 1-6) and the bottom (lanes 7-12) strands are shown. Lanes 1, 2, 11, 12 are $\mathrm{G}$ and $\mathrm{G}+\mathrm{A}$ Maxam and Gilbert sequence ladders used as markers. The amount of Esg protein used in the binding reaction was $0 \mathrm{ng}$ (lanes 3,7), $2.4 \mathrm{ng}$ (lanes 4,8), $12 \mathrm{ng}$ (lanes 5,9), and $60 \mathrm{ng}$ (lanes 6,10). (E) esg protein binds as a monomer. Proteins were preincubated in the binding buffer for $16 \mathrm{hr}$ at $4^{\circ} \mathrm{C}, 5$ fmoles of the wild-type probe was added to initiate binding, and the products analyzed by a gel mobility retardation assay. (Lane 1) Esg (75 pg); (lane 2) mixture of Esg and GST-Esg; (lane 3) GST-Esg (50 pg). Esg and GST-Esg formed complexes with distinct mobilities (labeled with arrowheads). No complex with intermediate mobility was detectable from the mixture.

pression vector alone did not affect the level of CAT activity, suggesting that esg itself does not affect basal transcription of the promoter used. Weak stimulation of CAT activity was observed when either the $d a$ or $s c$ expression vector was cotransfected. In contrast, cotransfection with both the $d a$ and $s c$ expression vectors greatly stimulated the CAT activity. This strong stimulation was repressed completely by the presence of the esg expression vector but not by the truncated esg derivative ( $\Delta z \mathrm{z})$. These results indicate that esg protein acts as a repressor of $\mathrm{Sc} / \mathrm{Da}$-dependent transcription.

\section{A mutation within the zinc finger reduces affinity for DNA and causes a loss-of-function phenotype}

To test whether the observed transcriptional regulatory activity of esg protein is relevant to its function in vivo, we studied the DNA-binding activity of an esg mutant. $e^{\text {esg }}{ }^{V S 8}$ is an ethylmethanesulfonate (EMS)-induced strong recessive mutation with an embryonic lethal phenotype (Hayashi et al. 1993). We sequenced this allele and found a single $\mathrm{G} \rightarrow \mathrm{E}$ amino acid substitution in the middle of the third zinc finger (Fig. 3A). X-ray crystallographic analyses of similar $\mathrm{C}_{2}-\mathrm{H}_{2}$-type zinc finger proteins suggest that the amino acid change occurred in the conserved $\alpha$-helix that makes critical contacts with DNA in the major groove (Pavletich and Pabo 1991, 1993|. To test the effect of this amino acid change on DNA-binding activity, the zinc finger region of esg $\mathrm{vs8}$ was produced in bacteria and its DNA-binding activity was compared with the wild-type protein (Fig. 3B). As expected, the mutant had an affinity $\sim 50$-fold weaker for the $\mathrm{E} 2$ box. Thus, high affinity for the $\mathrm{E} 2$ box is likely to be essential for esg function in vivo.

\section{Rescue of the esg mutant phenotype by pulses of esg expression}

The experiments described above demonstrated that esg protein can act as a transcription factor. We then asked how such a transcription factor performs the proposed inhibition of endoreplication in the larva. esg could reg- 
A

Reporter gene

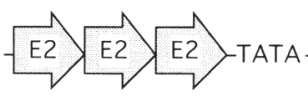

CAT

Effector gene

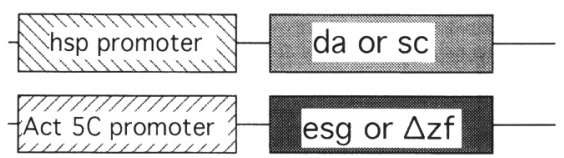

$\mathrm{B}$

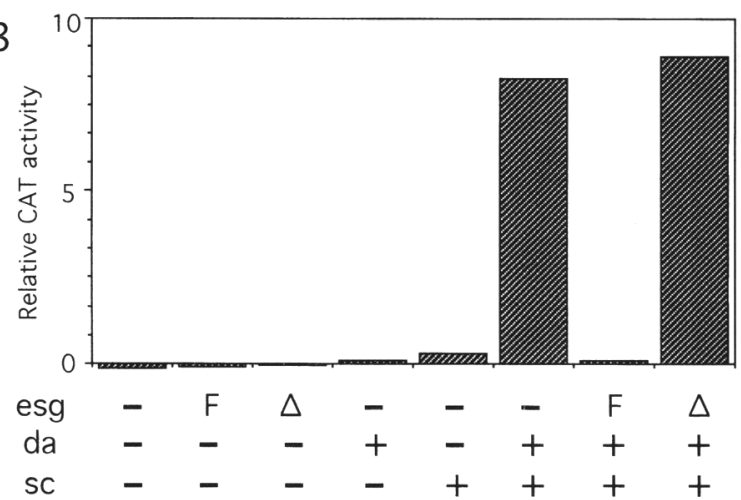

Figure 2. esg antagonizes transcriptional activation by $\mathrm{Sc} / \mathrm{Da}$ heterodimer. (A) A schematic illustration of the constructs used for the transfection experiment. The reporter gene is the bacterial CAT gene placed downstream of the Adh distal TATA box and three copies of the E2 box. The effector genes were da or sc cDNAs placed downstream of the Drosophila hsp 70 promoter, and esg or $\Delta z$ f ORF placed downstream of the Drosophila Act $5 \mathrm{C}$ promoter. $(B)$ The result of the CAT assay. Columns indicate the CAT activity of each sample that was transfected with the combination of the effector plasmids indicated below. $(F)$ Fulllength esg construct; $(\Delta) \Delta z f$ construct. The $y$-axis is in arbitrary units of CAT activity that were standarized with the $\beta$-galactosidase activity from cotransfected pAc-lacZ as an internal control.

ulate directly expression of genes essential for endoreplication. Alternatively, esg could act earlier to determine the fate of imaginal cells. We tried to resolve this issue by determining when esg function is required to inhibit endoreplication. Fly strains containing the esg gene under the control of the $h s p 70$ promoter (HS-esg) were constructed. After heat shock, these strains expressed esg protein ubiquitously with a molecular weight identical to that of native esg protein (Fig. 4C,D). A control construct (HS- $\Delta z \mathrm{f}$ ) lacking the carboxy-terminal half of the protein expressed a shorter protein in similar amount (Fig. 4D). Both proteins are localized to the nucleus (Figs. $4 \mathrm{C}$ and $7 \mathrm{G}$ ). The $\Delta z \mathrm{zf}$ construct was used as a control throughout the following experiments. The half-life of ectopically expressed esg protein was $\sim 2 \mathrm{hr}$ in embryo (see Materials and methods). A single heat shock $\left(37^{\circ} \mathrm{C}\right.$, $60 \mathrm{~min}$ ) applied at any time from embryogenesis to the pupal stage did not affect the viability of the HS-esg flies. Such adults showed no apparent morphological abnormality and were fertile.

The ability of HS-esg to rescue the esg mutant pheno- type was then tested. As described above, esg ${ }^{V S 8}$ contains an amino acid change within the zinc finger region. The $e g^{P 3}$ allele has a P-element insertion in the promoter region of the esg gene (S. Hayashi, unpubl.). Both alleles are recessive embryonic lethal, but their heteroallelic combination survives to the pharate adult stage. Abdominal histoblasts of esg ${ }^{V S 8} / \mathrm{esg}^{P 3}$ larvae undergo endoreplication and become polyploid, preventing the development of adult abdominal epidermis (Fig. 5D,E,F; Hayashi et al. 1993). HS-esg was introduced into this genetic background, and multiple heat shocks were applied during embryonic and larval stages. In larvae thus treated, the size of the abdominal histoblast nuclei and their DNA content were much smaller. Some were comparable to the wild-type diploid histoblasts (Fig. 5H,I). Such histoblasts apparently proliferate and properly differentiate during metamorphosis, as the amount of the adult type abdominal cuticle was significantly restored by HS-esg (Fig. 5G). This result demonstrates that overexpression of esg rescues the abdominal phenotype of

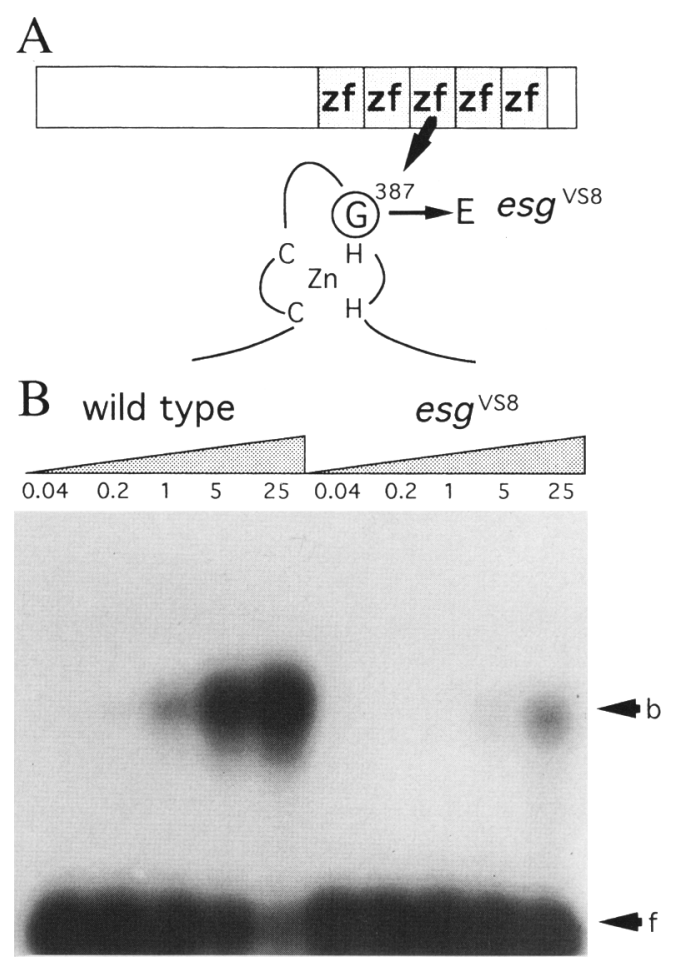

Figure 3. A missense mutation within the zinc finger reduces affinity for DNA. (A) Position of the amino acid substitution found in the esg ${ }^{V S 8}$ allele. A G ${ }^{387} \rightarrow \mathrm{E}$ substitution was found within the third zinc finger. This position corresponds to the amino-terminal half of the $\alpha$-helix thought to be inserted into the major groove of DNA to make base-specific contacts (Pavletich and Pabo 1993). (B) DNA-binding activity of the esg vs8 protein. The DNA-binding domain of esg ${ }^{\mathrm{VS} 8}$ was produced in bacteria, and its DNA-binding activity was compared with the wild-type protein. Ten fmoles of the wild-type probe was incubated with various amount of the wild-type or the mutant protein. The molar ratio of protein to probe is shown above each lane. 

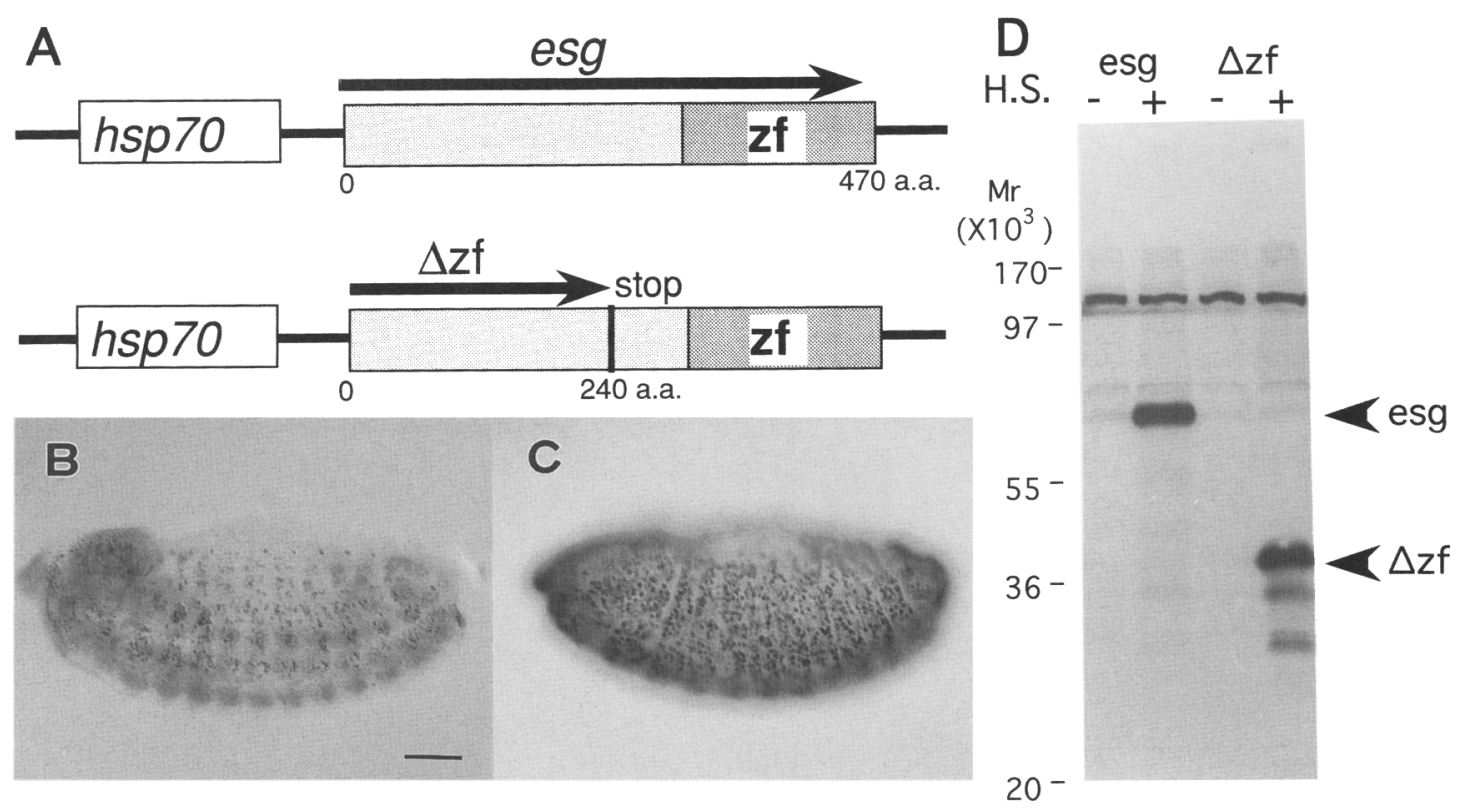

Figure 4. Construction of HS-esg lines. (A) Schematic illustration of the hsp70-esg fusion constructs. A translation termination codon was introduced to make the $\Delta z$ f construct encoding a 240-amino-acid truncated protein. (B) A wild-type stage 13 embryo stained with anti-esg antibody. Nuclear-localized esg expression is detectable in thoracic and genital imaginal discs. In addition, expression in the head, central nervous system, muscle, and tracheas can be seen. Most of the expression is transient and by stage 17, esg expression becomes restricted mainly to imaginal cells. Bar, $50 \mu \mathrm{m} .(\mathrm{C})$ A slightly older HS-esg embryo that was heat-shocked $\left(37^{\circ} \mathrm{C}\right.$, $60 \mathrm{~min} / 20 \mathrm{~min}$ before fixation. All cells express esg protein. (D) esg protein detected by Western blotting. Extracts were prepared from the HS-esg and HS- $\Delta$ zf embryos with or without heat treatment and analyzed by Western blotting using the anti-esg antibody and enhanced chemiluminescence detection. Strong heat induction of esg and $\Delta z$ f proteins is evident in the heat-shocked samples (marked by arrowheads). In addition, a weak band of endogenous esg protein is detectable in non-heat-shocked HS-esg and both HS- $\Delta z \mathrm{f}$ lanes. These bands comigrate with full-length esg protein from HS-esg and from Escherichia coli (not shown). The full-length esg protein migrated slower than its predicted molecular mass of $52 \mathrm{kD}$.

esg ${ }^{V S 8} /$ esg $^{p 3}$ and that the phenotype is attributable to the loss of esg function.

Having established the conditional rescue of the esg mutant phenotype by HS-esg, we then determined when the esg product is required for the rescue. To quantitate the rescue, we introduced HS-esg into esg $^{L 2} /$ esg $^{G W 2}$ heterozygote. esg $^{L 2}$ has a small deletion of the esg-coding region with no detectable esg protein expression. esg GW2 has a deficiency removing part of the upstream region of the esg gene (S. Hayashi, unpubl.). Flies heterozygous for these alleles are viable with reduced abdominal cuticle and bristles [number of male sternite bristles: in wild type, $59.5(n=10)$; in esg ${ }^{G W 2} /$ esg $^{L 2},[0.3(n=10)]$. Without a heat shock the number of sternite bristles in es$g^{G W 2} /$ esg $^{L 2}$ HS-esg was very low $[0.4(n=18)]$. When heat shocks were applied during the first 6 days of development, an increase in the bristle number was observed (Fig. 6). Both the average and the maximum number of bristles increased with more frequent heat shocks. Thus, a frequent induction of esg protein throughout the larval stages was required for efficient rescue. Assuming that the estimated 2-hr half-life of esg protein in the embryo also applies to the larva, there are still periods lacking induced esg protein in larvae heat-treated every 6 hr. This may explain why the rescue was incomplete.
This result suggests that the abdominal histoblasts require esg throughout the larval stage to remain diploid.

\section{esg overexpression inhibits endoreplication in salivary gland cells}

The HS-esg experiments described above suggest that esg normally inhibits endoreplication in the abdominal histoblasts, an imaginal tissue. We then determined whether esg is also able to inhibit endoreplication in the salivary gland, which is a larval tissue. Because pulses of esg expression in the HS-esg larvae did not affect the DNA content of the larval epidermal cells and the viability of the adults (data not shown), esg was expressed continuously in a tissue-specific manner using the Gal4upstream activating sequence (UAS) system (Brand and Perrimon 1993). One of the enhancer trap lines isolated by Brand and Perrimon showed Gal4 activity in the embryonic and larval salivary gland, as revealed by a UASlac $Z$ reporter. Fly strains carrying the esg gene under the control of a Gal4-responsive promoter were established (UAS-esg) and crossed to the salivary gland Gal4 line. Anti-esg staining revealed ectopic esg expression in the salivary glands beginning at stage 14 /Campos-Ortega and Hartenstein 1985; Fig. 7D|. Such embryos complete 


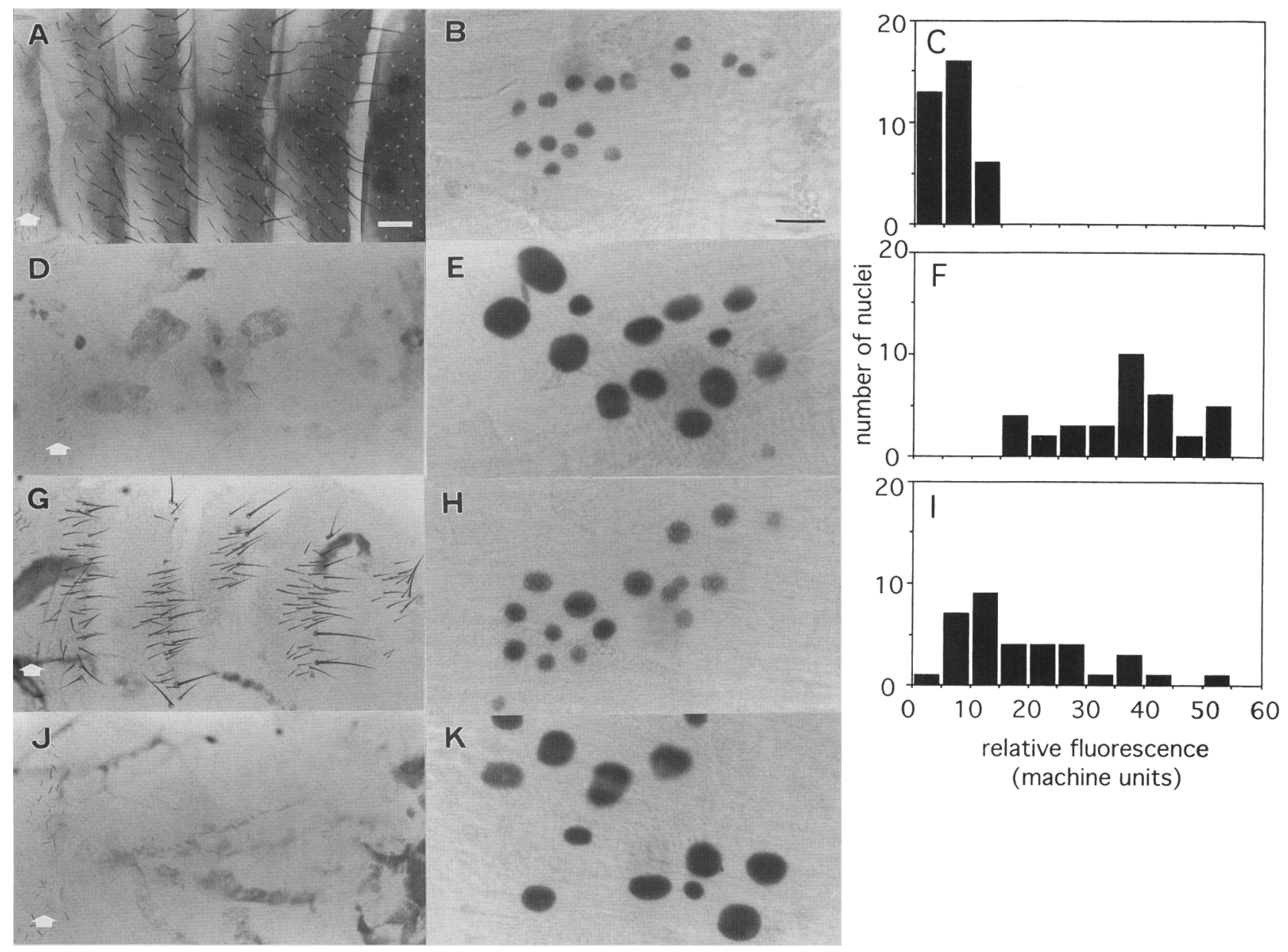

Figure 5. HS-esg rescues the esg mutant phenotype. The abdominal phenotype of Oregon-R $|A|$, esg $g^{P 3} /+(B, C), e^{P 3} / g^{P s} g^{V S 8}|D-F|$,

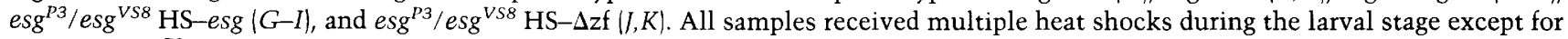
$A$ and $C$. esg $^{P 3} /+$ develops normally and serves as a wild-type control. $(A, D, G, I)$ First through sixth abdominal tergites of pharate adults. The adult cuticle and bristles are missing in esg $^{P 3} / \mathrm{esg}^{V S 8}$, except for $\mathrm{Al}$ (open arrows), which is less affected by these mutations $(D)$; instead, the abdomen was covered with thin cuticle. This phenotype was rescued by HS-esg $(G)$ but not by HS- $-\Delta f(J)$. $(B, E, H, K)$ $\mathrm{X}$-gal staining of abdominal histoblasts in late third-instar larvae. esg ${ }^{P 3}$ is an enhancer trap line that expresses nuclear localized $\beta$-galactosidase in the abdominal histoblasts. The nucleus of abdominal histoblasts in $\mathrm{esg}^{P 3} / \mathrm{esg}^{V S 8}$ is larger than wild type (E). HS-esg reduced the size of the abdominal histoblast nuclei $(H) \cdot\{C, F, I)$ Quantitation of DNA in the abdominal histoblast. DAPI fluorescence was quantitated and shown as histograms. Note that in $\operatorname{esg}^{P 3} / \operatorname{esg}^{V S 8}(F)$, no cell with a DNA content at the level of the diploid cells in esg ${ }^{P 3} /+(C)$ was found. HS-esg prevented the endo cycle, and the DNA content of many of the histoblasts remained at the diploid level $(I)$. esg $^{P 3} / \mathrm{esg}^{V S 8}$ HS-esg larvae cultured without heat shock appeared similar to esg $g^{P 3} / \mathrm{esg}^{V S 8}$. $(A) \mathrm{Bar}, 100 \mu \mathrm{m} ;(B) \mathrm{bar}, 25 \mu \mathrm{m}$.

embryogenesis and show a temperature sensitivity in larval growth. At $25^{\circ} \mathrm{C}$, most of the larvae died before the second instar. At $18^{\circ} \mathrm{C}$, many of them survived past metamorphosis. Figure 7, E and F, shows the salivary gland of larvae cultured at $18^{\circ} \mathrm{C}$. Ectopic esg expression resulted in a reduction of the size of the salivary gland. DAPI staining of the gland revealed a small nucleus with low DNA content, suggesting that endoreplication was inhibited by esg. Such inhibition was not observed in the larvae expressing Gal4 alone (Fig. $7 \mathrm{C}$ ) or the $\Delta$ zf protein (Fig. 7I), and only a mild effect was observed in the larvae expressing FTZ-Fl, a $\mathrm{C}_{2}-\mathrm{C}_{2}$-type zinc finger transcription factor (Lavorgna et al. 1991; data not shown). Although ectopic esg expression inhibited endoreplication, its effect was not complete at $18^{\circ} \mathrm{C}$. The nuclei of the salivary gland cells expressing esg were larger than those of the diploid cells in the salivary gland imaginal ring and the chromosomes were polytene (not shown).

To analyze the effect of esg on DNA replication more directly, a bromodeoxyuridine (BrdU) incorporation experiment was performed. Larvae were cultured at $25^{\circ} \mathrm{C}$ and fed with BrdU between 14 and $30 \mathrm{hr}$ after hatching. Although most salivary gland cells incorporated BrdU in the control larvae (Fig. 8A), most of the cells in the experimental salivary glands stained negative, suggesting esg inhibited endoreplication (Fig. 8B). However, a few cells in the experimental larvae stained to a similar extent as that of the control cells, suggesting that complete 


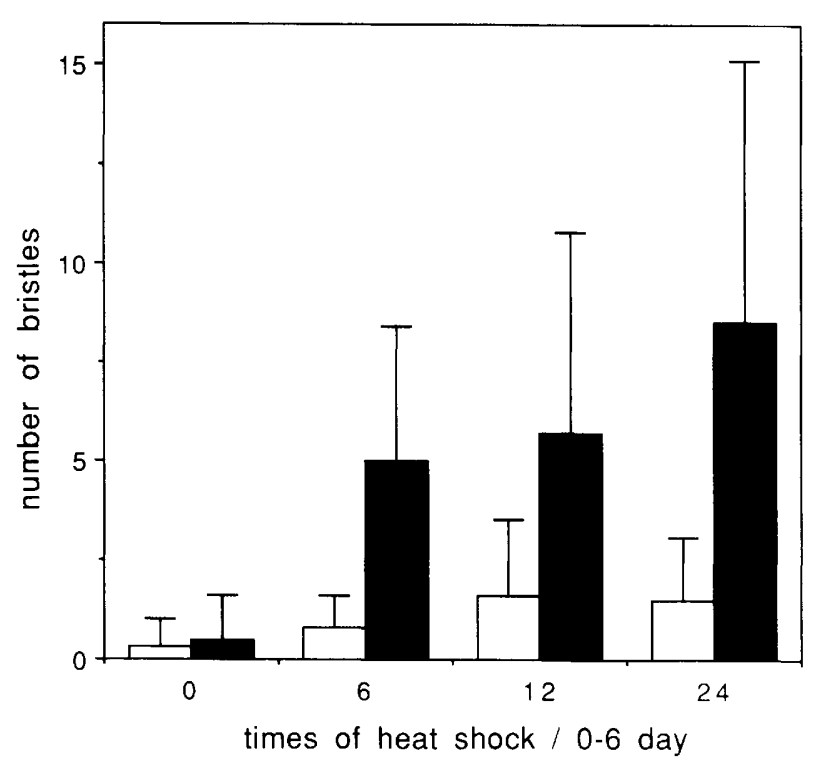

Figure 6. Heat shock-dependent rescue of $e s g^{\mathrm{GW} /} / \mathrm{esg}^{\mathrm{L2}}$ by HSesg. esg ${ }^{G W 2} /$ esg $^{L 2}$ (open bar) and esg ${ }^{G W 2} /$ esg $^{L 2}$ HS-esg (solid bar) were heat-shocked $\left(37^{\circ} \mathrm{C}, 30 \mathrm{~min}\right)$ during the first 6 days of development, and the numbers of abdominal sternite bristles were counted and plotted against the number of heat shocks. The average and standard deviation are shown for each sample. Maximum rescue by HS-esg was 24 bristles, which is $40 \%$ of wild type.

DNA replication had occurred in these cells /Fig. 8C; see Discussion).

\section{Discussion}

\section{esg encodes a transcriptional repressor}

We have shown that Esg binds to the E2 box and inhibits transcriptional activation by Sc/Da heterodimers. esg did not show any transcriptional regulatory activity by itself on the simple promoter used in this study, suggesting that esg protein alone does not interact with the basal transcriptional machinery in S2 cells. Therefore, simple competition with an activator for the same E2 box sequence would explain the inhibitory effect of esg protein. The relatively high affinity of Esg for the E2 box supports this idea. A similar competition mechanism has been proposed for the snail (sna) gene function. sna encodes a zinc finger protein with high similarity to esg and is known for its role in mesodermal formation (Boulay et al. 1987). Ip et al. (1992) have shown that spatial regulation of rhomboid transcription in neuroectoderm is dependent on bHLH activators and sna repressor acting at a common site containing $\mathrm{E}$ boxes. It is still possible, however, that esg may act as an activator with the aid of an unidentified cofactor in some situations.

At present, we do not know which particular bHLH protein is interacting with esg in imaginal cells. Da, however, is a candidate. da has been shown to be required for growth or survival of imaginal cells /Cronmiller and Cline 1987) and is expressed ubiquitously in embryos and in several larval tissues /Cronmiller and Cummings 19931.

esg inhibits the endo cycle in imaginal cell

In the esg ${ }^{v S 8} /$ esg $^{p 3}$ heterozygous larvae, the abdominal histoblasts become polyploid. We have shown that overexpression of esg protein reduces ploidy of the mutant histoblasts. This cannot be attributable to a general toxic effect of overexpression of a transcription factor, as HSesg did not affect larval growth in general, and the treated abdominal histoblasts underwent normal metamorphosis to form the adult epidermis. esg activity is required continuously throughout the larval period; furthermore, we have shown that esg expression can also inhibit endoreplication in the salivary gland, a larval tissue. These results strongly suggest that esg does not act at the level of imaginal cell fate determination. It is more likely that esg acts directly on a mechanism controlling endoreplication. Interestingly, we have observed that some cells in esg-expressing salivary glands overcome the inhibitory effect of esg and replicate DNA to the same extent as normal cells do (Fig. 8C). This all-or-none response may indicate that esg inhibited entry into $S$ phase, but once a cell has somehow overcome the effect of esg, $\mathrm{S}$ phase proceeds normally.

For the following reasons, we think the inhibitory action of esg is specific to endoreplication and not to DNA replication in the mitotic cell cycle. First, esg RNA expression is found in the imaginal discs of the embryo (Whiteley et al. 1992; Hayashi et al. 1993) and in the third-instar larva (Hayashi et al. 1993). Cells in imaginal discs are known to divide between these periods in the presence of the esg transcript. Second, we have observed that $\mathrm{S} 2$ cells transfected with esg expression vector replicate DNA and go through mitosis in the presence of high levels of esg protein (S. Hayashi, unpubl.). Taken together, it is likely that esg inhibits entry specifically into the $S$ phase of the endo cycle but not of the mitotic cycle.

\section{What controls entry into the endo cycle?}

Until now, very few studies have addressed the genetic control of the endo cycle. Initiation of the endo cycle is regulated both spatially and temporally in the embryo and in the early larva (Smith and Orr-Weaver 1991), suggesting a mechanism that responds to spatial and temporal cues to initiate endoreplication. Genetic analyses have shown that the known cell cycle regulators cdc2 and the string product, which are essential for mitosis, are not required for the endo cycle (Smith and OrrWeaver 1991; Stern et al. 1993). On the other hand, cyclin $E$, which is expressed before entry into $S$ phase, has been shown to be essential for DNA replication in both mitotic and endo cycles (Richardson et al. 1993; Duronio and O'Farrell 1994; Knoblich et al. 1994).

Our current hypothesis is that two distinct pathways exist permitting entry into the $S$ phase by activation of 


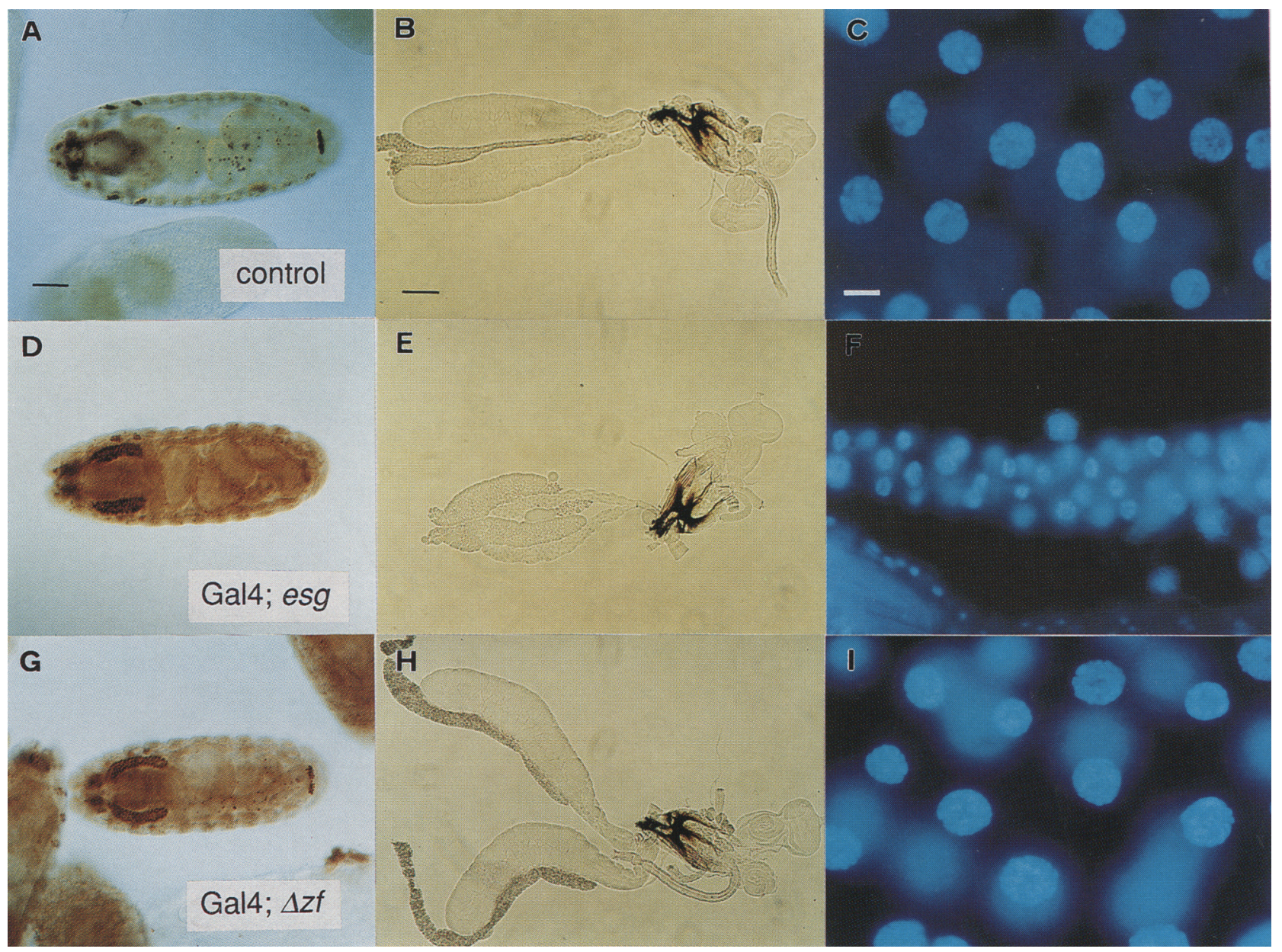

Figure 7. Ectopic esg expression inhibits growth of the salivary gland. esg was expressed ectopically in the larval salivary gland by the Gal4-UAS system. $(A)$ Oregon-R. $(B, C)$ Control fly carrying the Gal4 enhancer trap alone. $(D-F)$ Flies carrying the Gal4 enhancer trap and UAS-esg (Gal4; esg). (G-I) Flies carrying the Gal4 enhancer trap and UAS- $\Delta z \mathrm{f}$ (Gal4; $\Delta z \mathrm{f}$ ). The anti-esg staining of stage 16 embryos is shown in $A, D$, and $G$. Gal4-induced esg expression in the salivary gland is visible in $D$ and $G$. Note that both esg and the $\Delta z f$ protein were localized to the nucleus. $B, E$, and $H$ show the salivary glands (left) and the eye-antennal discs (right) of larvae cultured at $18^{\circ} \mathrm{C}$. Note that the size of the salivary gland in the Gal4;esg larva is reduced, whereas the size of the attached fat body and eye-antennal discs was normal $\langle E\rangle$. $C, F$, and $I$ shows the DAPI staining of the salivary glands. Note the reduction of the nuclear size in Gal4;esg $(F)$. (A) Bar, $50 \mu \mathrm{m} ;(B)$ bar, $200 \mu \mathrm{m} ;(C)$ bar, $25 \mu \mathrm{m}$.

cyclin $\mathrm{E}$. The first pathway (termed $\mathrm{X}$ ) allows both the $\mathrm{S}$ and $M$ phases and is active only in proliferating cells such as the imaginal disc but not in larval cells and abdominal histoblasts. Growth stimulation of such cells results in mitosis. The second pathway (termed Y) permits the $S$ phase but not the $M$ phase. Cells with an active $Y$ pathway enter the endo cycle when growth stimulated. The Y pathway is activated by unknown bHLH proteins that are present in both larval and imaginal cells during the transition from the mitotic to the endo cell cycle. The presence of esg protein will then repress the activation and restrict the activity of the $\mathrm{Y}$ pathway only in larval cells. Observations in this and our previous study (Hayashi et al. 1993) are consistent with this model. esg inhibits DNA replication in the salivary gland where the $Y$ pathway is active, but esg does not inhibit DNA replication in imaginal discs where the $\mathrm{X}$ pathway is active. In the esg $^{V S 8} /$ esg $^{P 3}$ abdominal histoblasts, where repression by esg is absent, the Y pathway becomes active to allow the histoblasts to become polyploid. In the esg ${ }^{V S 8} /$ esg $^{P 3}$ imaginal disc, both $\mathrm{X}$ and $\mathrm{Y}$ pathways are active, and the cells can still go through mitosis. In $\mathrm{raf}^{1}$; esg $\mathrm{eSS}^{\mathrm{V}} \mathrm{esg}^{P 3}$ imaginal disc, the $\mathrm{X}$ pathway becomes inactive because of the $r a f^{1}$ mutation, only the Y pathway is active, and the cells enter the endo cycle. Recently, Moreno and Nurse (1994) reported cloning of the rum $1^{+}$gene from the fission yeast Schizosaccharomyces pombe. Overexpression of rum $1^{+}$in $\mathrm{G}_{1}$ results in a polyploid cell, a situation similar to the endo cycle. A rum $1^{+}$-like gene active in the endo cycle may perform the function expected for the $\mathrm{Y}$ pathway. Identification of genes that interact with esg will be required to test this hypothesis. Our findings should provide a framework for a future study of the endo cycle. 


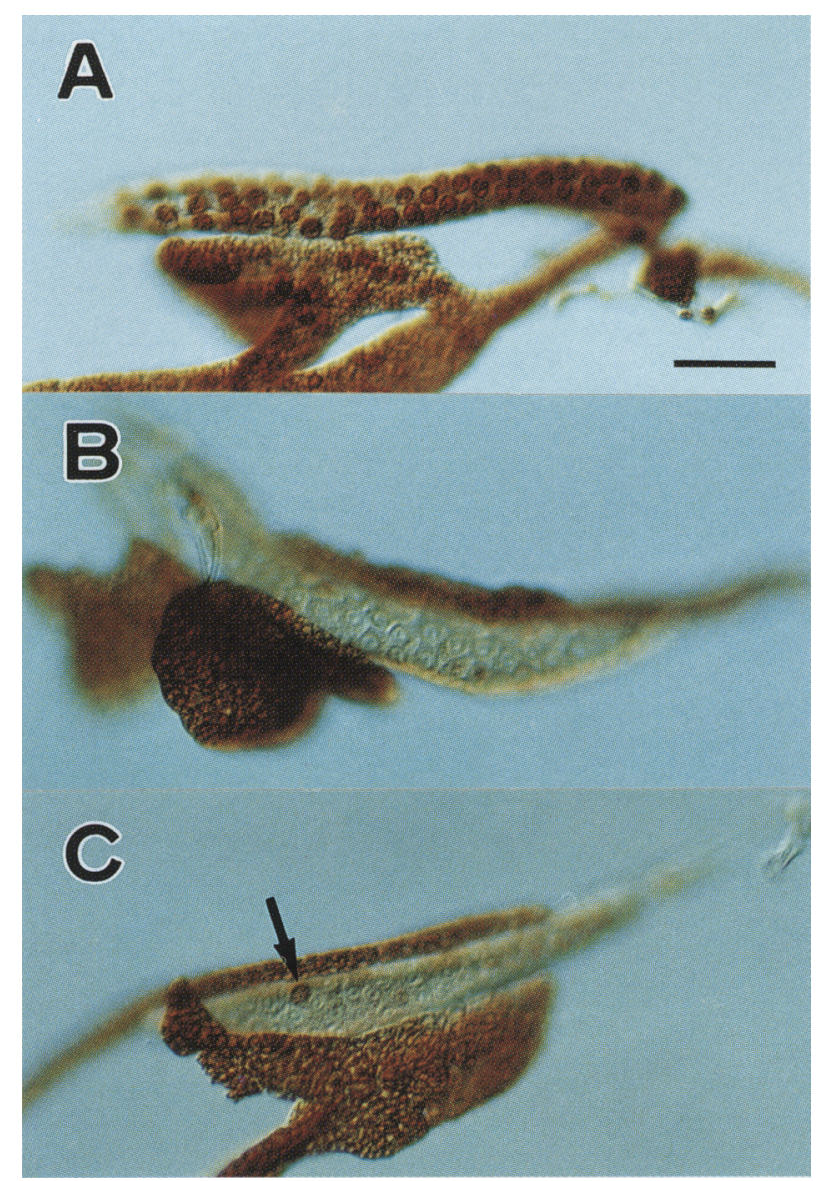

Figure 8. esg inhibits endoreplication. Larvae between 14 and $30 \mathrm{hr}$ after hatching were labeled with $\mathrm{BrdU}$ at $25^{\circ} \mathrm{C}$ and stained with anti-BrdU. $(A)$ A salivary gland of a control UAS-esg larva. Most of the cells are labeled. $(B, C)$ Two examples from Gal4; esg larvae. BrdU incorporation was hardly detectable. However, note the single strongly stained cell indicated by an arrow in $C$, which has escaped the inhibitory effect of esg. Bar, $25 \mu \mathrm{m}$.

endo cycle is set as a default in abdominal histoblast in Drosophila

The phenotype of the esg mutants suggests that in the abdominal histoblasts, as in the surrounding larval epidermal cells, the endo cycle is set as a default. esg can then suppress endoreplication in the abdominal histoblasts. Although polyploidy is commonly seen among most insect species, complete suppression of mitosis in the larval epidermis occurs only in limited orders such as cyclorrhaphous Diptera (Sehnal 1985). Larval epidermal cells grow by cell division in the Lepidoptera Manduca sexta, Bombyx mori, and Coleoptera Tenebrio molitor (Kato and Ohba 1977; Besson-Lavoignet and Delachambre 1981; Dyer et al. 1981). Such cells secrete larval, pupal, and adult cuticle. Therefore, these insects do not necessarily require abdominal histoblasts to form the adult abdomen. It has been proposed that species with a short life cycle have evolved to use exclusively the endo cycle as an efficient means for larval growth at the cost of losing developmental versatility (Sehnal 1985). Such a specialization would then require a set of pluripotent cells capable of forming the adult. It is conceivable that control mechanisms promoting and inhibiting the endo cycle may have evolved simultaneously only recently.

\section{Materials and methods}

Fly stocks

The esg mutants $\left(e s g^{P 3}, e s g^{V S 8}, e^{L g^{L 2}}\right.$, and $\left.e s g^{G W 2}\right)$ used for this study were described by Hayashi et al. (1993). The P[Gal4] and $\mathrm{P}[\mathrm{UAS}-\mathrm{lacZ}]$ lines were described by Brand and Perrimon (1993). Other genotypes were described by Lindsley and Zimm (1992).

\section{Production of recombinant protein}

esg wild-type (esg ${ }^{\mathrm{wt}}$ ) and esg ${ }^{\mathrm{vS} 8}$ mutant (esg ${ }^{\mathrm{vs}}$ ) recombinant proteins were prepared using an Escherichia coli expression system (Studier and Moffatt 1986). Fragments containing the carboxy-terminal region of the esg open reading frame (ORF) (amino acids 306-470) and flanked by an NdeI site at the $5^{\prime}$ end were PCR amplified from esg ${ }^{\text {wt }}$ or esg ${ }^{\text {vs } 8}$ clones and inserted into $\mathrm{pET}-23 \mathrm{~b}$ (Novagen) vector. Recombinant proteins were purified by the method of Marston (1987) with some modifications. The induced bacterial pellet was resuspended in lysis buffer $[50 \mathrm{~mm}$ Tris- $\mathrm{HCl}(\mathrm{pH} 8 \mid, 1 \mathrm{~mm}$ EDTA, $100 \mathrm{~mm} \mathrm{NaCl}, 1$ $\mathrm{mM}$ dithiothreitol, $1 \mathrm{mM}$ phenylmethylsulfonyl fluoride [PMSF)] and lysed by addition of lysozyme (final $200 \mu \mathrm{g} / \mathrm{ml}$ ), deoxycholic acid $(1 \mathrm{mg} / \mathrm{ml})$, and DNase I $(5 \mu \mathrm{g} / \mathrm{ml})$. Collected inclusion bodies were washed with $4 \mathrm{M}$ urea, $100 \mathrm{~mm}$ Tris-HCl (pH 8.6) buffer. Recombinant proteins were solubilized by treatment with $6 \mathrm{M}$ guanidium hydrochloride in buffer A $[20 \mathrm{~mm}$ HEPES (pH 7.9), $100 \mathrm{~mm} \mathrm{KCl,} 10 \mu \mathrm{M} \mathrm{ZnCl}_{2}, 20 \%$ glycerol, $0.1 \%$ NP-40, $1 \mathrm{~mm}$ dithiothreitol, $1 \mathrm{mM}$ PMSF], renatured by dialysis against buffer $\mathrm{A}$, and stored at $-80^{\circ} \mathrm{C}$. The proteins thus prepared were $>80 \%$ pure as estimated by Coomassie brilliant blue staining of a SDS-polyacrylamide gel. Full-length esg protein was produced from a $\mathrm{pET} 3$ a vector containing the esg ORF with the Ndel site at the initiator methionine. The yield from this construct was poor and it was used only as a marker for the experiment of Figure 4D.

For GST-Esg fusion protein, esg-coding region lamino acids 236-466) was inserted into pGEX-2T vector. The fusion protein was prepared by the method of Smith and Corcoran (1990). Glutathione-Sepharose $4 \mathrm{~B}$ resin (Pharmacia) was used for affinity purification of the fusion protein.

\section{In vitro DNA-binding experiments}

The esg-binding consensus sequence was derived from sequences selected by affinity to esg protein from a pool of oligonucleotides containing 15 random sequences in the middle as described by Gogos et al. (1992). The binding reactions were performed in binding buffer [12 mM HEPES (pH 7.9), $100 \mathrm{~mm}$ $\mathrm{KCl}, 10 \mu \mathrm{MM} \mathrm{ZnCl}_{2}, 12 \%$ glycerol, $1 \mathrm{~mm}$ dithiothreitol, $20 \mu \mathrm{g} /$ $\mathrm{ml}$ of bovine serum albumin, and $1-100 \mu \mathrm{g} / \mathrm{ml}$ of poly[d(I-C)] with various amounts of esg protein. ${ }^{32} \mathrm{P}$-Labeled probe was incubated with esg protein, and oligomers bound by the protein were separated by electrophoresis through a $0.8 \%$ agarose gel in $500 \mathrm{~mm}$ Tris, $40 \mathrm{~mm}$ borate, and $1 \mathrm{~mm}$ EDTA at $7 \mathrm{~V} / \mathrm{cm}$ for $2 \mathrm{hr}$. The oligomers eluted from the agarose gel were amplified by PCR and then used for the next selection cycle. After the fourth 
round of selection, DNA fragments were subcloned into Bluescript II vector and sequenced. The consensus sequence was derived from the sequences of 49 clones.

The gel mobility retardation assay was performed as described above using the binding buffer containing $100 \mu \mathrm{g} / \mathrm{ml}$ of poly $[\mathrm{d}(\mathrm{I}-\mathrm{C})]$. The double-strand oligomers used for the mobility retardation assay are described below. Probe or wild-type competitor was GCGGCCTGACAGGTGCTTTG with a TCGA 5' overhang on both strands. Mutant competitor was GCGGCCTGCACACTGGTTTG.

DNase I footprinting was performed by the method of Kasai et al. (1992). DNA-protein binding conditions were the same as those used for the gel mobility retardation assay.

The dissociation constant of Esg was determined as described by Ueda et al. (1992). In a $10-\mu$ l reaction mixture, a twofold dilution series of probe (final, $0.028-0.45$ fmoles $/ \mu$ l) was incubated with a constant amount of esg protein $(0.5$ fmoles $/ \mu 1)$. Bound and free probe were separated by electrophoresis, quantitated by Fuji BAS2000, and the dissociation constant was calculated from the Scatchard plot.

\section{Immunological procedures}

Production of anti-esg serum To make an esg-poly-histidine fusion protein (esg-E), a DNA fragment for the amino-terminal 241 amino acids was inserted into pET23b and the fusion protein was prepared from BL21 DE3 host. The protein was purified by $\mathrm{Ni}^{+}$affinity chromatography and a FPLC mono Q column. Donryu rats were immunized with $0.2 \mathrm{mg}$ of esg-E mixed with Freund's complete adjuvant and boosted three times by injection of esg-E mixed with Freund's incomplete adjuvant. Serum prepared from the rats was used directly for immunostaining at 1000- to 2000-fold dilution.

Western blotting and embryo immunostaining Embryos at 0-20 hr after egg laying (AEL) were treated with or without heat shock $\left(37^{\circ} \mathrm{C}, 1 \mathrm{hr}\right)$. Dechorionated embryos were sonicated in phosphate-buffered saline. Extracts from $\sim 40$ embryos were separated by $10 \%$ SDS-PAGE and transferred to a nitrocellulose filter. After blocking with TBSTw [50 mM Tris- $\mathrm{HCl}(\mathrm{pH} 7.5)$, $150 \mathrm{~mm} \mathrm{NaCl}, 1 \mathrm{~mm}$ EDTA, $0.1 \%$ Tween 20 ] containing $2.5 \%$ skim milk powder, the filter was incubated with rat anti-esg antibody (1000-fold dilution), biotin-conjugated anti rat IgG (400-fold dilution; Jackson Laboratory), and ABC complex (200fold dilution, Vectastain elite kit). After each incubation, the filter was washed with TBSTw buffer. Peroxidase activity was detected by enhanced chemiluminescence (ECL detection reagent; Amersham).

Embryo immunostaining was performed as described by Hayashi et al. (1993) with the same antibody combinations as in the Western blotting. Staining was developed in diaminobenzidine (DAB) solution.

\section{Germ-line transformation and analyses of esg overexpression}

The $\sim 2.0$-kb XbaI-EcoRV fragment used for esg overexpression is a composite of genomic and cDNA. The initiator methionine is preceded by CAAAATG and a XbaI restriction site that was engineered by PCR. For the $\Delta z$ construct, a frameshift mutation was introduced by cleavage of an internal EcoRI site and filling in with Klenow fragment and dNTPs. This treatment resulted in the insertion of a stop codon after the amino acid 240 .

Heat-induced expression esg or $\Delta \mathrm{zf}$ ORF was inserted into the pCaSpeR-hs vector (Thummel and Pirrota 1991). These constructs were injected into y $\mathrm{Df}(1) \mathrm{w}^{67 c 1}$ hosts by the germ-line
P-transformation method of Rubin and Spradling (1982). Lines containing an insert on the second chromosome were used for most experiments. When stained with anti-esg, ectopic esg expression is detectable in HS-esg embryos $2 \mathrm{hr}$ after heat shock at $37^{\circ} \mathrm{C}$ for $30 \mathrm{~min}$. The expression becomes undetectable after $3 \mathrm{hr}$, therefore, we estimated the half-life of esg protein to be $\sim 2 \mathrm{hr}$.

To examine the effect of unrestricted esg expression, progeny of a cross between HS-esg/CyO and Oregon-R were collected at 3-hr intervals for $24 \mathrm{hr}$ and heat-shocked $\left(37^{\circ} \mathrm{C}, 1 \mathrm{hr}\right)$. Such treatment did not change the ratio of $\mathrm{Cy}^{+} / \mathrm{Cy}^{-}$of hatched adults when compared with the control $\Delta z \mathrm{f}$. HS-esg/ + adults appeared normal and were fertile. Similarly, heat shock applied 1-6 days AEL had no effect on viability and adult morphology.

To rescue the esg mutant phenotype, P[HS-esg] or P[HS- $-\Delta \mathrm{zf}]$ was introduced into the esg ${ }^{V S 8}$ chromosome. esg ${ }^{V S 8} \mathrm{P}[\mathrm{HS}-$ esg]/ $G l a B c$ adults were crossed with $e^{P 3} / G l a B c$ adults. Embryos at $0-$ to 6 -hr AEL were collected and given multiple heat shocks $\left(37^{\circ} \mathrm{C}\right.$ for $1 \mathrm{hr}$, every $\left.6 \mathrm{hr}\right)$ until AEL 6 day. Late third-instar larvae of the treated progeny, which have $\mathrm{BC}^{+}$phenotype, were dissected and the nuclei of larval histoblasts were visualized by staining for $\beta$-galactosidase activity (from $e^{2} g^{P 3}$ enhancer trap). To measure ploidy, larval abdominal histoblasts were identified by staining with rabbit anti- $\beta$-galactosidase (Cappel) and FITCconjugated anti-rabbit IgG as described by Hayashi et al. (1993). Quantification of DAPI fluorescence was carried out for 35 histoblast nuclei for each genotype by Zeiss MPM800. To observe the cuticle, abdomens of pharate adults were dissected and mounted in Hoyer's mountant. The rescue experiment was also carried out in the esg allelic background (esg ${ }^{L 2} /$ esg $\left.^{G W 2}\right)$. The animals were given heat shocks $\left(37^{\circ} \mathrm{C}, 30 \mathrm{~min}\right)$ every 6,12 , or 24 $\mathrm{hr}$ during 0-6 days AEL. The rescue was quantified by the number of male sternite bristles.

Salivary gland expression esg or the $\Delta$ zf-coding region was inserted into the pUAST vector (Brand and Perrimon 1993), and transgenic lines were established as described above. The Gal4 enhancer trap line provided by Brand and Perrimon has an insertion in the $\mathrm{X}$ chromosome and expresses Gal4 in salivary gland cells from embryonic through larval stages. $\mathrm{y}^{+} \mathrm{P}[\mathrm{Gal} 4] /$ Binscinsy females were crossed with P[UAS-esg] or P[UAS- $\Delta \mathrm{zf}]$ males. After culturing at $18^{\circ} \mathrm{C}, \mathrm{y}^{+}$third-instar larvae were dissected, fixed with $4 \%$ paraformaldehyde, and stained with DAPI. In all cases, $\mathrm{y}^{-}$larvae had normal salivary glands.

The BrdU incorporation experiment was performed by the method of Smith and Orr-Weaver (1991). Larvae were cultured at $25^{\circ} \mathrm{C}$ and fed on a BrdU-containing diet $10.8 \%$ agar, $5 \%$ sucrose, $1 \%$ yeast extract, $0.5 \%$ yeast, $0.5 \mathrm{mg} / \mathrm{ml}$ of BrdU) during 14-30 hr after hatching. These larvae were dissected, and their salivary glands were fixed in Carnoy's fix (ethanol/acetic acid, $3: 1 \mid$ for $15 \mathrm{~min}$. Incorporated BrdU was visualized using an antiBrdU antibody (Bu5.1, Progene) and DAB detection.

\section{Transfection experiment}

Transfection of S2 cells and CAT assays were done essentially as described (Winslow et al. 1989). The CAT reporter plasmid pD-33A3 was constructed by inserting three copies of the wildtype oligonucleotide used for the gel retardation shift experiment into the SalI site of pD-33 (Jaynes and O'Farrell 1988). phs-da and phs-ac were constructed by inserting da and sc cDNA downstream of the $h s p 70$ promoter (K. Hoshijima, K. Inoue, and Y. Shimura, pers. comm.). pAc-esg and pAc- $\Delta z \mathrm{f}$ were constructed by inserting the esg or $\triangle \mathrm{zf}$ ORF into pPAc (Krasnow et al. 1989). Two micrograms of pD-33A3, $1 \mu \mathrm{g}$ of pAc-lacZ, and combinations of $5 \mu \mathrm{g}$ each of phs-da, phs-ac, 
pAc-esg, and pAc- $\Delta$ zf were mixed and the total DNA content was adjusted to $20 \mu \mathrm{g}$ by addition of Bluescript SK $\mid-$ ) plasmid and transfected into S2 cells. When any effector plasmid was omitted from the mixture, it was replaced with pAc. After $36 \mathrm{hr}$, extracts were prepared from the cells by three freeze-thaw cycles and $1 / 20$ was used to measure $\beta$-galactosidase activity (Miller 1992). Extracts corresponding to equal $\beta$-galactosidase activity were used for the CAT assay.

Autoradiographs were quantitated by a Fuji BAS 2000 image analyzer. Three independent sets of experiments gave essentially the same result. Similar levels of inhibition were observed with $0.5 \mu \mathrm{g}$ of pAc-esg.

\section{Sequencing of an esg allele}

esg ${ }^{V S 8}$-coding region was PCR amplified from $e g^{V S 8} / e^{P S} g^{P 2}$ genomic DNA using primers corresponding to positions 645-665 of the upper strand and 2473-2493 of the lower strand (Whiteley et al. 1992). Because the placW ${ }^{+}$enhancer trap element in esg ${ }^{\mathrm{P}}$ is inserted downstream of the upper primer, only esg ${ }^{\mathrm{vS} 8}$ was amplified efficiently. The amplified fragment was subcloned into the Bluescript vector, and four clones were mixed for sequencing using the Sequenase kit (U.S. Biochemical). In addition to the $\mathrm{G}^{387} \rightarrow \mathrm{E}$ change specific for esg ${ }^{\mathrm{VS} 8}$, we found two amino acid differences in our sequence (isol and Oregon- $R$ ) from the sequence reported by Whiteley et al. (1992): $\mathrm{P} \rightarrow \mathrm{Q}$ at amino acid position 149 and $M \rightarrow I$ at position 196 , both of which are homologous changes. We consider these changes to be neutral polymorphisms.

\section{Acknowledgments}

We thank Andrea Brand and Nobert Perrimon for providing strains and plasmids for the Gal4 system before publication, Kunio Inoue for $d a$ and $s c$ expression vectors, Hitoshi Ueda for advise on DNA-binding experiments, and Takehide Murata and Hitoshi Ueda for the UAS-FTZFl strain. We are grateful to Jun-ichi Tomizawa (National Institute of Genetics, Mishima, Japan), Alan Shirras (Lancaster University, Lancaster, U.K.), and Mark Seielstad (Harvard University, Boston, Massachusetts, USA) for critically reading the manuscript. This work has been supported by grants from the Ministry of Science, Education, and Culture, Tokyo, Japan, to S. Hirose and S. Hayashi.

The publication costs of this article were defrayed in part by payment of page charges. This article must therefore be hereby marked "advertisement" in accordance with 18 USC section 1734 solely to indicate this fact.

\section{References}

Bate, M. and A. Martinetz-Arias. 1991. The embryonic origin of imaginal discs in Drosophila. Development 112: 755-761.

Besson-Lavoignet, M.T. and J. Delachambre. 1981. The epidermal cell cycle during the metamorphosis of Tenebrio molitor L. (Insecta Coleoptera). Dev. Biol. 83: 255-265.

Boulay, J.L., C. Dennefeld, and A. Alberga. 1987. The Drosophila developmental gene snail encodes a protein with nucleic acid binding fingers. Nature 330: 395-398.

Brand, A.H. and N. Perrimon. 1993. Targeted gene expression as a means of altering cell fates and generating dominant phenotypes. Development 118: 401-415.

Bryant, P.J. 1978. Pattern formation in imaginal discs. In The genetics and biology of Drosophila (ed. M. Ashburner and T.R.F. Wright), vol. 2c, pp. 230-335. Academic Press, London, UK.
Cabrera, C.V. and M.C. Alonso. 1991. Transcriptional activation by heterodimers of the achaete-scute and daughterless gene products of Drosophila. EMBO I. 10: 2965-2973.

Campos-Ortega, J.A. and V. Hartenstein. 1985. The embryonic development of Drosophila melanogaster. Springer-Verlag, Berlin, Germany.

Cohen, B., E.A. Wimmer, and S.M. Cohen. 1991. Early development of leg and wing primordia in the Drosophila embryo. Mech. Dev. 33: 229-240.

Cohen, S.M. 1993. Imaginal disc development. In The development of Drosophila melanogaster (ed. M. Bate and A. Martinez-Arias|, vol. 2, pp. 747-842. Cold Spring Harbor Laboratory Press, Cold Spring Harbor, New York.

Cronmiller, C. and T.W. Cline. 1987. The Drosophila sex determination gene daughterless has different functions in the germ line versus the soma. Cell 48: 479-487.

Cronmiller, C. and C.A. Cummings. 1993. The daughterless gene product in Drosophila is a nuclear protein that is broadly expressed throughout the organism during development. Mech. Dev. 42: 159-169.

Doren, M.V., P.A. Powell, D. Pasternak, A. Singson, and J.W. Posakony. 1992. Spatial regulation of proneural gene activity: Auto- and cross-activation of achaete is antagonized by extramacrochaetae. Genes \& Dev. 6: 2592-2605.

Duronio, R.J. and P.H. O'Farrell. 1994. Developmental control of a Gl-S transcriptional control in Drosophila. Development 120: 1503-1515.

Dyer, K.A., W.B. Thornhill, and L.M. Riddiford. 1981. DNA synthesis during the change to pupal commitment of Manduca epidermis. Dev. Biol. 84: 425-431.

Gogos, J.A., T. Hsu, J. Bolton, and F.C. Kafatos. 1992. Sequence discrimination by alternatively spliced isoforms of a DNA binding zinc finger domain. Science 257: 1951-1955.

Hartenstein, V. and Y.N. Jan. 1992. Studying Drosophila embryogenesis with P-lacZ enhancer trap lines. Wilhelm Roux's Arch. Dev. Biol. 201: 194-220.

Hartwell, L.H. and T.A. Weinert. 1989. Checkpoints: Controls that ensure the order of cell cycles events. Science 246: 629634.

Hayashi, S., S. Hirose, T. Metcalfe, and A. Shirras. 1993. Control of imaginal cell development by the escargot gene of Drosophila. Development 118: 105-115.

Hope, I.A. and K. Struhl. 1987. GCN4, a eucaryotic transcriptional activator protein, binds as a dimer to target DNA. EMBO I. 6: 2781-2784.

Ip, Y.T., R.E. Park, D. Kosman, E. Bier, and M. Levine. 1992. The dorsal gradient morphogen regulates stripes of rhomboid expression in the presumptive neuroectoderm of the Drosophila embryo. Genes \& Dev. 6: 1728-1739.

Jaynes, J.B. and P.H. O'Farrell. 1988. Activation and repression of transcription by homoeodomain-containing proteins that bind a common site. Nature 336: 744-749.

Kasai, Y., J.R. Nambu, P.M. Lieberman, and S.T. Crews. 1992. Dorsal-ventral patterning in Drosophila: DNA binding of snail protein to the single-minded gene. Proc. Natl. Acad. Sci. 89: 3414-3418.

Kato, Y. and Y. Ohba. 1977. Temporal pattern of changes in mitotic frequency in the epidermis and other larval tissues of Bombyx mori. I. Insect. Physiol. 23: 1095-1098.

Knoblich, A., K. Sauer, L. Jones, H. Richardson, R. Saint, and C.F. Lehner. 1994. Cyclin E controls S phase progression and its down-regulation during Drosophila embryogenesis is required for the arrest of cell proliferation. Cell 77: 107-120.

Krasnow, M.A., E.E. Saffman, K. Kornfeld, and D.S. Hogness. 1989. Transcriptional activation and repression by Ultrabithorax proteins in cultured Drosophila cells. Cell 57: 
1031-1043.

Lavorgna, G., H. Ueda, J. Clos, and C. Wu. 1991. FTZ-F1, a steroid hormone receptor-like protein implicated in the activation of fushi tarazu. Science 252: 848-851.

Lindsley, D.L. and G.G. Zimm. 1992. The genome of Drosophila melanogaster. Academic Press, San Diego, CA.

Marston, F.A.O. 1987. The purification of eukaryotic polypeptides expressed in Escherichia coli. In DNA cloning: A practical approach (ed. D.M. Glover), vol. 3, pp. 59-88. IRL Press, Oxford, UK.

Miller, J.H. 1992. A short course in bacterial genetics. Cold Spring Harbor Laboratory Press, Cold Spring Harbor, New York.

Moreno, S. and P. Nurse. 1994. Regulation of progression through the Gl phase of the cell cycle by the rum $1^{+}$gene. Nature 367: 236-242.

Murre, C. and D. Baltimore. 1992. The helix-loop-helix motif: Structure and function. In Transcriptional regulation (ed. S. McKnight and K. Yamamoto), pp. 861-879. Cold Spring Harbor Laboratory Press, Cold Spring Harbor, New York.

Murre, C., P.S. McCaw, H. Vaessin, M. Caudy, L.Y. Jan, Y.N. Jan, C.V. Cabrera, J.N. Buskin, S.D. Hauschka, A.B. Lassar, H. Weintraub, and D. Baltimore. 1989. Interactions between heterologous helix-loop-helix proteins generate complexes that bind specifically to a common DNA sequence. Cell 58: $537-544$.

Pavletich, N.P. and C.O. Pabo. 1991. Zinc finger-DNA recognition: Crystal structure of a Zif268-DNA complex at $2.1 \AA$. Science 252: 809-817.

- 1993. Crystal structure of a five-finger GLI-DNA complex: New perspectives on zinc fingers. Science 261: 17011707.

Richardson, H.E., L.V. O'Keef, S.I. Reed, and R. Saint. 1993. A Drosophila G1-specific cyclin E homologue exhibits different mode of expression during embryogenesis. Development 119: 673-690.

Roseland, C.R. and H.A. Schneiderman. 1979. Regulation and metamorphosis of the abdominal histoblasts of Drosophila melanogaster. Wilhelm Roux's Arch. Dev. Biol. 186: 235265.

Rubin, G.M. and A.C. Spradling. 1982. Genetic transformation of Drosophila with transposable element vectors. Science 218: 348-353.

Sehnal, F. 1985. Growth and cell cycles. In Comprehensive insect physiology biochemistry and pharmacology (ed. G.A. Kerkut and L. Gilbert), vol. 2, pp. 1-86. Pergamon Press, New York.

Sherr, C.J. 1993. Mammalian $G_{1}$ cyclins. Cell 73: 1059-1065.

Smith, A.V. and T.L. Orr-Weaver. 1991. The regulation of cell cycle during Drosophila embryogenesis: The transition to polyteny. Development 112: 997-1008.

Smith, D.B. and L.M. Corcoran. 1990. Expression and purification of glutathione-S-transferase fusion proteins. In Current protocols in molecular biology (ed. M. Ausubel, R. Brent, R. Kingston, D. Moore, J. Seidman, J. Smith, and K. Struhl), vol. 16.7 , pp. 1-8. Wiley Interscience, New York.

Stern, B., G. Ried, N.J. Clegg, T.A. Grigliatti, and C.F. Lehner. 1993. Genetic analysis of the Drosophila cdc2 homolog. Development 117: 219-232.

Studier, F.W. and B.A. Moffatt. 1986. Use of bacteriophage T7 RNA polymerase to direct selective high-level expression of cloned genes. I. Mol. Biol. 189: 113-130.

Thummel, C.S. and V. Pirrotta. 1991. New CaSpeR P-element vectors. Drosophila Inf. Newslett. 2:.

Ueda, H., G.-C. Sun, T. Murata, and S. Hirose. 1992. A novel DNA-binding motif abuts the zinc finger domain of insect nuclear hormone receptor FTZ-F1 and mouse embryonal long terminal repeat-binding protein. Mol. Cell. Biol. 12: 5667-5672.

Varmuza, S., V. Prideaux, R. Kopthary, and J. Rossant. 1988. Polyten chromosomes in mouse trophoblast giant cells. Development 102: 127-134.

Whiteley, M., P.D. Noguchi, S.M. Sensabaugh, W.F. Odenwald, and J.A. Kassis. 1992. The Drosophila gene escargot encodes a zinc finger motif found in snail-related genes. Mech. Dev. 36: $117-127$.

Winslow, G.M., S. Hayashi, M. Krasnow, D.S. Hogness, and M.P. Scott. 1989. Transcriptional activation by the Antennapedia and fushi tarazu proteins in cultured Drosophila cells. Cell 57: 1017-1030.

Younossi-Hartenstein, A., U. Tepass, and V. Hartenstein. 1993. Embryonic origin of the imaginal discs of the head of Drosophila melanogaster. Wilhelm Roux's Arch. Dev. Biol. 203: 60-73. 


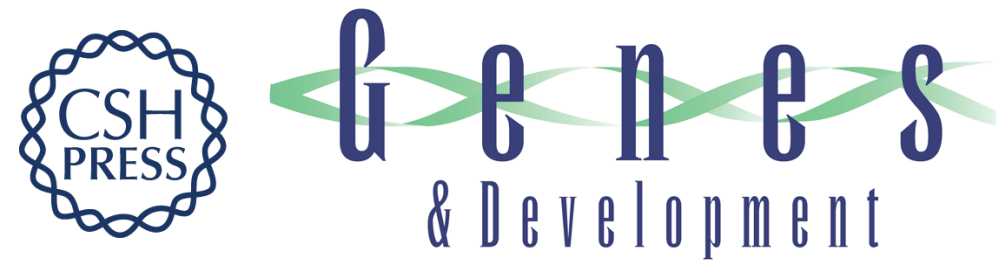

\section{Diploidy of Drosophila imaginal cells is maintained by a transcriptional repressor encoded by escargot.}

N Fuse, S Hirose and S Hayashi

Genes Dev. 1994, 8:

Access the most recent version at doi:10.1101/gad.8.19.2270

References This article cites 39 articles, 18 of which can be accessed free at:

http://genesdev.cshlp.org/content/8/19/2270.full.html\#ref-list-1

License

Email Alerting

Service

Receive free email alerts when new articles cite this article - sign up in the box at the top right corner of the article or click here.

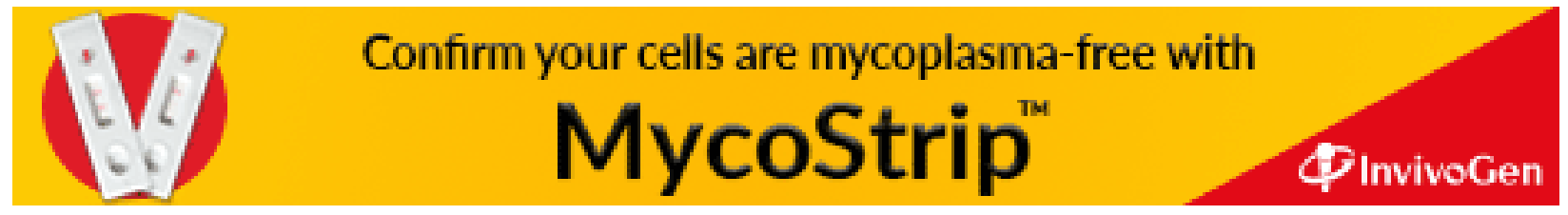

